\title{
MOVILIDAd DE TRABAJAdores AgRícolas \\ de Guatemala a la frontera sur de MÉxico \\ EN TIEMPOS DE CONTROL MIGRATORIO ${ }^{1}$
}

\section{Mobility of Agricultural Workers of Guatemala to the Southern Border of MeXico in Migratory Control Times}

\section{Martha Luz Rojas Wiesner ${ }^{2}$}

Resumen: Con este artículo se busca exponer algunos argumentos relacionados con los efectos de la política de control y contención migratoria en México que, mediante el llamado ordenamiento de flujos migratorios, ha afectado la movilidad transfronteriza de trabajadores y de trabajadoras de Guatemala que tradicionalmente han llegado a Chiapas para desempeñar actividades agrícolas. La ejecución de las medidas de control, encaminadas en particular a la población que busca llegar a los Estados Unidos atravesando México, ha tenido distintas repercusiones en la movilidad de laboral, así como en la documentación y en los procesos de contratación y de inserción laboral en Chiapas de trabajadores agrícolas de Guatemala, lo que merece un análisis particular y ser documentado con estudios específicos así como con análisis más cuidadosos y críticos de las fuentes de información de las que se dispone, dado que los datos no permiten visualizar con claridad dicho efecto, aunque hay distintas evidencias para sostener un descenso en su número.

\footnotetext{
${ }^{1}$ Nota del editor: se respeta íntegramente el texto final que entregó la autora, con los dictámenes académicos atendidos.

${ }^{2}$ Investigadora del Departamento de Sociedad y Cultura de El Colegio de la Frontera Sur, San Cristóbal de Las Casas, Chiapas. Correo electrónico: mrojas@ecosur.mx

Fecha de recepción: 0102 17; Fecha de aceptación: 030617.
}

(cc) BY-NC-ND Páginas 83-118. 
Palabras clave: Movilidad laboral transfronteriza, Guatemala-México, trabajadores agrícolas, política migratoria.

Abstract: This article seeks to present some arguments related to the effects of the migration control and containment policy in Mexico, which, through the so-called ordering of migratory flows, has affected the cross-border mobility of working men and working women in Guatemala which have traditionally come to Chiapas to perform agricultural activities. The implementation of the control measures, directed in particular to the population that seeks to reach the United States through Mexico, has had different repercussions on labor mobility, as well as documentation and on the processes of recruitment and labor insertion in Chiapas of agricultural workers Guatemalan which deserves a particular analysis and be documented with specific studies as well as with more careful and critical analyzes of the sources of information available, since the data do not allow a clear visualization of this effect, Although there are different evidences to say that there is a decrease in its number.

Keywords: Cross-border labor mobility, Guatemala-Mexico, agricultural workers, migration policy.

\section{Introducción}

Los trabajadores y las trabajadoras agrícolas (TA) de Guatemala han contribuido a la economía de Chiapas desde fines del siglo XIX, por lo que su movilidad laboral tiene un carácter histórico. Varios trabajos dan cuenta de esta historia y de la expansión de la economía cafetalera, así como de las estrategias usadas por los finqueros para asegurar la mano de obra que necesitaban para cimentar esta economía, basada en mayor medida en el cultivo del café, demandante de un uso intensivo de fuerza laboral (ver, por ejemplo, Wasserstrom, 1976; Spenser, 1984; García de León, 1985; Castillo y Casillas, 1988; Ordoñez, 1993; Martínez, 1994; Bartra, 1995; Grollova, 2002). Si bien no se cuenta con estadísticas históricas, que permitan estimar el número 
de trabajadores guatemaltecos que ha contribuido a esta expansión, hay algunos trabajos que pueden contribuir en ese sentido, al hacer referencia a algunas cifras y a la necesidad de abundante mano de obra para la cosecha del café (ver, por ejemplo, Martínez, 1994).

Más recientemente, se puede dar cuenta de la importancia de esta fuerza laboral mediante las estadísticas administrativas del Instituto Nacional de Migración (INM) y con los resultados de la Encuesta sobre Migración en la Frontera Sur de México (EMIF Sur), ${ }^{3}$ fuentes que proveen información diferente y no comparable entre sí. Con la primera fuente, se captan dos tipos de datos, unos referidos al número de permisos que expide la autoridad migratoria por ańo, y otros al número de trabajadores y trabajadoras. La segunda fuente, por su parte, ha contribuido a conocer algunas características de la inserción laboral de trabajadores transfronterizos a Chiapas —ocupaciones y algunas características sociodemográficas y laborales.

El número de trabajadores y trabajadoras que se documentan ante las autoridades migratorias mexicanas es un dato muy reciente, el cual se ha podido obtener a partir de la expedición del permiso individual en formato de una credencial. Poder contabilizar el número de trabajadores y trabajadoras constituye un dato relevante, dado que permite un acercamiento al volumen de trabajadores/as de origen guatemalteco que, de manera aproximada, llegan a Chiapas, lo cual ayudaría a matizar la alusión magnificada a enormes y distintos volúmenes de trabajadores y trabajadoras que se ha difundido por distintos medios, como se mencionará más adelante. Por otra parte, si se tiene el dato del número de trabajadores y el número de permisos, se podría tener una idea más precisa del promedio de veces por ańo que un trabajador o una trabajadora ingresa a México; un dato relacionado con la circularidad migratoria ${ }^{4}$ y la importancia de este flujo migratorio en la economía

\footnotetext{
${ }^{3}$ La Encuesta sobre Migración en la Frontera Sur de México (EMIF SUR) es una encuesta continua que se lleva a cabo desde 2004 en puntos muy específicos, contando algunos en la franja Soconusco-Guatemala, y que permite captar información sobre flujos laborales de Guatemala a México (http://www.colef.mx/emif/).

${ }^{4}$ Que puede ser definida de manera general como "la reiteración del movimiento migratorio a lo largo de un periodo relativamente corto de tiempo, lo que se erige como principal distintivo frente a otros tipos de movilidad, a pesar de incorporar otros atributos como la bilateralidad, la temporalidad y la continuidad” (López-Sala y Godenau, 2015:34)
} 
del estado de Chiapas. Sin embargo, la información es limitada y su calidad requiere revisión. Si bien en la última década tanto el Instituto Nacional de Migración como la Unidad de Política Migratoria (UPM), ambas dependientes de la Secretaría de Gobernación, han avanzado en el mejor registro y sistematización, es necesario ser cautos en el uso y análisis de la información.

Precisamente, debido a este proceso de mejoramiento de datos, al menos de los registros de quienes usan un permiso migratorio para trabajar en México, se plantean algunos interrogantes. Como se verá más adelante, las estadísticas relativas a los eventos o entradas no parecen ser muy claras respecto a la dinámica que se observa cotidianamente en el estado de Chiapas, entidad federativa a donde llega el mayor número de trabajadores y trabajadoras de origen guatemalteco que, con distintas temporalidades, se ocupa en actividades productivas en algunas de las regiones de esta entidad. ${ }^{5}$ Esto se ha prestado a distintas interpretaciones, varias muy optimistas, respecto a la dinámica laboral transfronteriza $^{6}$ en Chiapas, que se han hecho con cifras o cantidad de eventos que dan cuenta de la movilidad laboral transfronteriza ${ }^{7}$ en la frontera sur, llámense "entradas", en las estadísticas oficiales de INM, o “cruces", en la EMIF Sur.

\footnotetext{
${ }^{5}$ También se produce movilidad laboral hacia otras regiones de la frontera sur de México, pero el volumen y la intensidad en la circularidad es distinta. Si bien es significativa para la producción de determinadas actividades, como el cultivo de la caña de azúcar, en términos comparativos, la afluencia de fuerza laboral guatemalteca es menor a la que se dirige al Soconusco. Una línea de investigación específica sobre la movilidad laboral en la franja fronteriza de México con Belice es desarrollada por Martha García Ortega (ver, por ejemplo, García, 2013).

${ }^{6}$ La dinámica transfronteriza alude a las interacciones sociales en un territorio limítrofe entre dos países o región transfronteriza, que se puede dar en condiciones asimétricas o desiguales de poder (Bustamante, 1989). Estas interacciones pueden ser de distinto tipo, pero aquí se destacan las que se producen por la movilidad de jornaleros/as en busca de trabajo en Chiapas. Lo fronterizo no sólo alude a una línea o franja territorial divisoria precisamente delimitada - border o frontera limite-, sino que, además, hace referencia a un territorio o a una región en expansión - frontier o frontera frente- (De Vos, 2002, en Rojas, 2010). Según Castillo, las fronteras son al mismo tiempo ámbitos de rupturas y de continuidades, es decir, regiones que se extienden y que adquieren dimensiones transfronterizas e identidades propias, que las distinguen de los territorios que separan (Castillo, 2002, en Rojas, 2010).

${ }^{7}$ Para este artículo, se hace referencia a la movilidad de trabajadores y trabajadoras que viven en Guatemala, pero que llegar a trabajar a localidades de Chiapas, ya sea de manera temporal o estacional, o bien de manera cotidiana — commuting — en distintas actividades.
} 
Si se analizan con detalle las estadísticas del INM, con los elementos que se pueden obtener de las publicaciones oficiales o de las bases de datos de la misma fuente, es posible observar algunas situaciones que ameritan atención y que pueden ser planteadas como hipótesis de investigación: 1) el volumen de trabajadores y de trabajadoras de origen guatemalteco no tiene una correspondencia con el número de eventos —entradas, cruces o permisos_- cifras que se suelen usar acríticamente, de manera incorrecta, como sinónimos, al usar este último número para aseverar que hay un incremento en número de trabajadores/as y, por tanto, en la fuerza laboral de origen guatemalteco en la región, 2) contrariamente a lo que parecen representar los datos de las entradas de migrantes, hay una disminución en el volumen de trabajadores/as que se documentan con un permiso migratorio - hoy, Tarjeta de Trabajador Fronterizo, o TTF- 3) esta disminución está asociada a varios factores, entre los cuales destacan las medidas de contención y de control migratorio, entre las que se pueden incluir acciones de las autoridades migratorias relacionadas con la llamada "erradicación del trabajo infantil”, 4) estos factores pueden estar produciendo varios efectos: a) una reorientación espacial del flujo migratorio desde el origen hacia otros destinos, b) un cambio en el estatus migratorio, ${ }^{8}$ c) una reorientación en la inserción laboral del sector primario al comercio y a los servicios, y d) una mayor vulnerabilidad a la explotación laboral y a otras formas de violencia y discriminación como resultado de la mayor precarización de las condiciones de vida y de trabajo en Chiapas. A esto se suma que, en Chiapas, la producción de café ha pasado por varias crisis -de productividad, de precios, por factores ambientales y plagas, $\mathrm{y}$ que ahora la producción del grano demanda menor cantidad de mano de obra guatemalteca.

Teniendo en cuenta este contexto de cambios producidos en los últimos años en la dinámica de la movilidad laboral transfronteriza de Guatemala a México, entonces, en este artículo se exponen algunas reflexiones sobre los efectos del control migratorio en la movilidad

\footnotetext{
${ }^{8}$ Específicamente, lo que se ha evidenciado en trabajo de campo es que hay trabajadores/as con hijos menores de 16 años, que tradicionalmente se documentaban con el permiso del INM, pero que ya no lo hacen. Llegan directamente a algunas fincas en las que no se ha restringido el trabajo de menores de 16 años.
} 
transfronteriza, así como en la documentación de trabajadores transfronterizos y en los procesos de su contratación e inserción laboral en México, con énfasis en los efectos sobre los trabajadores y las trabajadoras agrícolas (TA). Las medidas de control, que se han emprendido en especial para contener el ingreso de migrantes que intentan llegar a otros estados de México o a los Estados Unidos sin documentación migratoria, ha tenido distintas repercusiones en la movilidad laboral, lo que merece un análisis particulary ser documentado con investigaciones futuras y con análisis más cuidadosos de las fuentes de información de las que disponemos, dado que las mismas pueden tener lecturas incorrectas sobre la inserción laboral guatemalteca en Chiapas. Estudios que, también, deberán hacerse para conocer lo que sucede tanto en los lugares de destino como en los de origen.

Con estas reflexiones se busca continuar indagando por los efectos del control a la movilidad de migrantes, quienes suelen pasar desapercibidos/as, porque ex profeso se les invisibiliza —al enfocarse en ciertos flujos migratorios- o porque ellos mismos o ellas mismas tratan de pasar invisibles o desapercibidos/as como una estrategia para que no se les regrese o deporte a sus lugares de origen, desde donde vienen porque necesitan el trabajo y porque en México se ha demandado esta fuerza laboral. Hay que seguir insistiendo en la necesidad de hacer visibles las condiciones de explotación y de precariedad extrema que enfrentan los trabajadores y las trabajadoras de Guatemala en las actividades agrícolas que desempeñan en México. ${ }^{9}$

Este artículo se basa en los resultados de al menos dos proyectos de investigación y del seguimiento de los mismos: "La participación de mujeres y menores en la migración laboral agrícola guatemalteca en la región del Soconusco, Chiapas", y en el proyecto dedicado al caso de la migración a México dentro de un proyecto más general llamado "Avanzando

\footnotetext{
${ }^{9}$ Una situación que no sólo afecta a la fuerza laboral proveniente de Guatemala, también a la mexicana y de otras procedencias, aunque en este último caso el número de quienes se ocupan en el sector primario, en comparación con la presencia de migrantes de Guatemala, pueda ser muy bajo. Situación que, además, no sólo afecta a migrantes sin documentación migratoria, también a quienes la tienen. El documento migratorio no garantiza ni un mejor pago ni mejores condiciones laborales. Para el caso de la población originaria de Chiapas, no se puede perder de vista que cerca de $43 \%$ de la población en edad de trabajar en dicha entidad federativa se ocupa en el sector primario, según el Censo de Población y Vivienda de 2010 del INEGI.
} 
en los Derechos de las Mujeres Migrantes en América Latina y el Caribe: los casos de Chile, Argentina, Costa Rica, República Dominicana y México”. El primero se llevó a cabo entre 1999 y 2002, con financiamiento del Sistema Regional de Investigación Benito Juárez del Consejo Nacional de Ciencia y Tecnología (Conacyt). El segundo es un proyecto financiado por el International Development Research Centre (IDRC) de Canadá que se llevó a cabo entre 2007 y 2012. Los dos proyectos han tenido seguimientos. Del primero se han hecho dos monitoreos (2007 y 2012) a las condiciones de vida y de trabajo de los y las TA, y el tercero se encuentra en curso. Del segundo proyecto se hace actualmente un monitoreo. ${ }^{10}$

\section{Las preocupaciones por la seguridad nacional y el control migratorio en la frontera sur}

Las preocupaciones por la llamada "seguridad nacional" en México han generado una serie de acciones y programas que, las autoridades de migración en coordinación con otras dependencias de gobierno, han emprendido para la "administración" o "gestión" de flujos migratorios documentados ${ }^{11}$ y para la contención de personas sin documentación migratoria. Una amplia literatura se ha dedicado en los últimos ańos a esta temática, en particular por las implicaciones que este tipo de

\footnotetext{
${ }^{10}$ Si bien este artículo es de mi autoría, precisa señalar que varios de los argumentos son parte de resultados de investigación y de reflexiones, conjuntas y en distintos foros, sobre la movilidad laboral, con énfasis en migración de mujeres guatemaltecas. En este trabajo, hemos contado con la asistencia de varias personas que han participado en proyectos de los que hemos sido responsables o colaboradores, apoyándonos con encuestas, entrevistas, observación, contactos, que son insumos importantes para dar seguimiento a la situación de los y las migrantes de Guatemala en México.

${ }^{11}$ Según Thomas Lothar Weiss y Rodolfo Franco, ex representante en México de la Organización Internacional para las Migraciones, la gestión migratoria "comprende, en un sentido amplio, todas las regulaciones, prácticas y normas estatales relativas a la admisión, salida y residencia de extranjeros a un territorio determinado. Estas normas, regulaciones y prácticas estatales determinan y dan forma institucional a la voluntad estatal, y capacidades de gobierno, para llevar a cabo tareas de control migratorio, al mismo tiempo que establecen los límites de la acción del Estado, asentados en normas internacionales y nacionales de derechos humanos e individuales" (Weiss y Franco, 2013: 179). Varias de las demandas en México de las organizaciones de la sociedad civil se han encaminado a cuestionar el énfasis en el control desde esta perspectiva, y a abogar por políticas migratorias integrales con enfoque en el desarrollo (ver, por ejemplo, Sin Fronteras, 2008).
} 
medidas ha tenido en la seguridad de las personas migrantes, quienes han sido víctimas de todo tipo de violencias y, de manera creciente, han tenido que enfrentar distintos riesgos y amenazas que han acentuado su vulnerabilidad y precariedad (ver, por ejemplo, Castillo y Toussaint, 2010, Isacson et al., 2014, Basok et al., 2015).

Una larga lista de programas y acciones de contención y de control de migrantes en México, puede ser elaborada, pero, a manera de ilustración, aquí sólo se mencionan algunas de las que se han ejecutado desde fines de la década de 1990: el plan de "Sellamiento de la Frontera Sur” (1998), el "Plan Sur” (junio de 2001), el plan piloto entre México y Guatemala de "Repatriación segura y ordenada" (junio de 2001), los distintos acuerdos y memorandos de entendimiento con los gobiernos de El Salvador, Honduras, Guatemala y Nicaragua para la repatriación segura y ordenada —algunos vigentes desde mayo de 2005-, los Manuales y Procedimientos para el otorgamiento de visas y permisos migratorios en México — publicados y reformados durante los tres últimos lustros - incluyendo los derivados de la promulgación de la Ley de Migración vigentes desde fines de 2012, entre otros (INM, 2005; Rojas y De Vargas, 2014).

En cuanto a la "gestión de flujos", con la finalidad de lograr lo que el gobierno de México considera una "movilidad ordenada", en la frontera sur se ha promovido la expedición de permisos para residentes regionales y para trabajadores fronterizos, de Belice y Guatemala. Este tipo de permisos no es nuevo; ${ }^{12}$ sin embargo, en 2014, la promoción

${ }_{12}$ Para la movilidad de residentes fronterizos de Guatemala y Belice, el INM expide desde 2012 la Tarjeta de Visitante Regional que, como su nombre lo dice, puede ser tramitada por personas que hayan nacido o sean residentes permanentes en estos dos países. Este tipo de documentación se promovió desde principios de la década de 2000, como Forma Migratoria de Visitante Local (FMVL), que se expedía sólo para residentes de municipios de Guatemala estrictamente fronterizos. Este permiso, expedido por las autoridades migratorias mexicanas, coexistió con el "pase local” expedido por las autoridades migratorias de Guatemala, por lo que muchas personas usaban la denominación indistintamente. Sin embargo, a partir de 2008, el gobierno mexicano no aceptó el pase local guatemalteco, como una medida de "ordenamiento", y comenzó a exigir la presentación de la FMVL que, a partir de entonces, se expedía en formato tipo credencial con vigencia de cinco ańos, para los residentes de los municipios fronterizos de los dos países limítrofes. Para la movilidad de trabajadores fronterizos, desde 2012, el INM expide la Tarjeta de Trabajado Fronterizo (TTF), de cuyos antecedentes haremos referencia en la siguiente sección. 
de su expedición se usó como argumento para una línea estratégica del llamado Programa Integral Frontera Sur ${ }^{13}$ enfocada a la "facilitación” en la documentación migratoria; "facilitación" que ya se había expresado en otros momentos, como en 2005, con la "Propuesta de política migratoria integral de la Frontera Sur de México", mediante la cual se buscaba regularizar a los dos grupos de población ya mencionados — trabajadores y visitante-. En el caso de los trabajadores fronterizos se pretendía, al mismo tiempo, tener un control sobre trabajadores y trabajadoras que se ocupaban en actividades distintas a la agrícola (INM, 2005).

Estos dos tipos de permiso se ubican en la categoría de condiciones de estancia de visitantes. De este modo, se reforzó la exigencia a trabajadores temporales y a residentes fronterizos de Guatemala de portar el permiso migratorio correspondiente para su ingreso a México. Con estas medidas, entonces, el estado mexicano ha buscado regular el ingreso y permanencia de "no-nacionales", mediante disposiciones que, en la práctica, producen una diferenciación en la movilidad, no sólo en términos espaciales y temporales, sino además en cuanto a las actividades que se pueden realizar y los recursos y derechos a los cuales se puede acceder. De este modo, se producen "categorías de extranjeros" (López, 2006:2), y al mismo tiempo, irregularidad migratoria (González, 2010). En particular, aquellas personas que no pueden pagar los costos de los trámites para una regularización migratoria o para pagar la renovación de sus documentos son altamente vulnerables a la irregularidad y a las consecuencias que esto implica.

Durante muchos años, se había podido cruzar el límite fronterizo entre Guatemala y México sin mayores dificultades, al menos así lo percibía la mayoría de los habitantes de la franja fronteriza. Con el establecimiento de la frontera entre ambos países se delimitó

${ }^{13}$ El 7 de julio de 2104, en Catazajá, Chiapas, el presidente de México, Enrique Peña Nieto, anunció el Programa Integral Frontera Sur, con el que buscaba proteger y salvaguardar los derechos humanos de los migrantes que ingresan y transitan por México, así como ordenar los cruces internacionales para incrementar el desarrollo y la seguridad de la región. El Programa ha causado múltiples controversias, en particular las relacionadas con las líneas de acción relativas al paso de migrantes seguro y ordenado, ordenamiento fronterizo y seguridad para migrantes, y protección social a migrantes. Mediante el citado programa se incrementó notoriamente el número de deportaciones y el número de operativos (Knippen, Boggs y Meyer, 2015). 
administrativamente un territorio hermanado social y culturalmente, en el que, además, subsisten lazos de consanguinidad y familiaridad. Sin embargo, en 2008, cuando se dio la instrucción de no permitir el paso de Guatemala a México si no tenían un documento migratorio, personas que tradicionalmente se habían movido en el territorio fronterizo sin papeles - cotidianamente o por temporadas-, se vieron en la necesidad de hacer el trámite para obtenerlos, pero otros no lo hicieron o no podían hacerlo. Algunas de las personas que entrevistamos, nos decían, que antes no sabían de "papeles". Otras personas que ya vivían en México no querían un documento para visitante, pero no podían pagar multas y el costo de la expedición de uno como residente.

Al lenguaje cotidiano se incorporó el vocablo "ilegales" para quienes cruzaban el río Suchiate u otras demarcaciones, en el mismo año en que entraba en vigor la reforma de varios artículos de la Ley General de Población que penalizaban el ingreso y permanencia en México sin documentos migratorios, para ser tipificados como una falta administrativa (2008). De este modo, se producía un tipo de irregularidad migratoria. Según Noelia González, "la migración irregular no es una realidad independiente o una simple consecuencia de entrar sin autorización en un Estado, sino que se produce en un contexto marcado por unas estructuras legales y políticas determinadas y en unas circunstancias socio-históricas particulares" (2010: 672).

De acuerdo con De Genova, la "ilegalidad" —o irregularidad, sin comillas_, no sólo hace referencia a un estatus jurídico relacionado con un estado-nación y sus leyes de inmigración, naturalización y ciudadanía; la "ilegalidad" de las personas migrantes, según el autor, designa "una condición sociopolítica específicamente espacializada "14", de modo que esta situación se vive a través de un fuerte temor a la probabilidad de la deportación —o deportabilidad (2004: 161). De esta forma, las leyes o las políticas no sólo producen categorías de extranjeros (López, 2006), producen irregularidad y sujetos deportables (González, 2010; De Genova, 2002, 2004). Esta producción, del que el "ordenamiento" o gestión de flujos es parte, no sólo deriva en irregularidad por no tener documentos migratorios, también entre quienes los tienen. Al

$\overline{{ }^{14} \text { Cursivas del autor }}$ 
respecto, Noelia González señala que el límite entre un estatus regular y uno irregular puede ser difuso (González, 2010). Incluso, aun teniendo documentos migratorios, puede haber otros tipos de irregularidad producidas por las mismas disposiciones que, por ejemplo, pueden restringir la movilidad para realizar determinadas actividades y para moverse en ciertos espacios o territorios. En el caso que nos ocupa, el control migratorio, entre otros factores, ha incidido en la movilidad y en la afluencia de trabajadores y trabajadoras agrícolas de Guatemala a México.

\section{Los trabajadores y las trabajadoras agrícolas de Guatemala}

Aunque en los últimos ańos, en Chiapas ha habido restricciones migratorias que han afectado la movilidad laboral, los trabajadores y las trabajadoras de origen guatemalteco que se dedican a actividades agrícolas constituyen un flujo migratorio que sigue conservando un carácter estacional y de retorno; la mayoría se desplaza sólo durante períodos específicos de acuerdo con los ciclos agrícolas de los cultivos de las unidades productivas a las que llegan a trabajar. Esto no significa que no haya trabajadores y trabajadoras de origen guatemalteco, e incluso de otras nacionalidades, que ya vivan en Chiapas y se dediquen a actividades agropecuarias. Una parte vive en las propias unidades productivas, en particular en las llamadas fincas donde se les reconoce como "acasillados" o "permanentes". En lustros recientes, personas de origen salvadoreño y hondureño, que ya viven en Chiapas, también se han incorporado a estas actividades. En algunos de nuestros proyectos hemos evidenciado esta presencia, en entrevistas relacionadas con otros temas — por ejemplo, regularización migratoria-, aunque no se ha realizado aún un estudio específico de esta inserción laboral.

Si bien hay trabajadores y trabajadoras que desempeñan actividades relacionadas con la ganadería y la pesca, la casi totalidad se ocupa en actividades agrícolas, en las distintas fases del cultivo de una variedad de productos, ya sean de ciclo corto o largo, o bien sean de exportación o de consumo local. Sin embargo, es el ciclo anual del cultivo del café el que rige en buena medida la estacionalidad de la movilidad laboral guatemalteca al estado de Chiapas. En la cosecha de café se produce 
la mayor afluencia del ciclo agrícola — septiembre-enero-, aunque en meses específicos otros productos tienen un peso significativo, tal como sucede con la caña de azúcar, cuya zafra incide en el volumen de trabajadores durante enero (Ángeles, 1998, 2000, 2010; Rojas, 2012).

La fuerza laboral de origen guatemalteco ha sido mayoritaria y fundamental para la economía del estado de Chiapas, tanto de la región del Soconusco, a donde sigue llegando la mayor parte, como de otras regiones donde se ubican algunas de las fincas y ejidos que contratan mano de obra de Guatemala, como la Frailesca, la región Sierra Mariscal, la Meseta Comiteca Tojolabal y la Costa,${ }^{15}$ por ejemplo (Ángeles, 2010).

Sobre las características de los y las TA hay algunos estudios al respecto, como Casillas y Castillo, 1987; Ángeles y Castillo, 1998; Rojas y Ángeles, 2002; INM, 2011, entre otros. Igualmente, desde 2004, se dispone de la información generada mediante la EMIF Sur ${ }^{16}$; con la cual se captan datos para varios flujos migratorios laborales, en función de la dirección de los mismos, entre los cuales se puede hacer un análisis específico para los y las TA de Guatemala, considerando que los datos aluden a eventos migratorios y a información que se capta por los principales puntos de internación terrestre desde Guatemala a México. Igualmente, la EMIF Sur tiene la particularidad de captar información relativa a personas mayores de 15 ańos que trabajan o buscan trabajo en localidades fronterizas del estado de Chiapas, tengan o no documentación migratoria. La EMIF considera los cruces de dos modalidades de trabajadores: 1 ) trabajadores temporales o estacionales que vienen a México a trabajar por periodos de varios días — se enfatizará en este grupo- - y 2) trabajadores residentes fronterizos que llegan a realizar sus jornadas diarias y se regresan el mismo día. ${ }^{17}$

\footnotetext{
${ }^{15}$ Según la última división socioeconómica del estado de Chiapas en 15 regiones (Secretaría de Gobierno de Chiapas, 2011).

${ }^{16}$ Denominada entre 2004 y 2008 como Encuesta de Migración en la Frontera GuatemalaMéxico (EMIF GUAMEX).

${ }^{17}$ Datos que pueden ser consultados en la sección "Migrantes procedentes de México a Guatemala”, en Tabulados Emif Sur Serie Histórica 2004-2014, en el sitio electrónico de la encuesta (ver Colef et al., s.f.). La fuente se actualiza de manera frecuente, por lo que la sección puede ir cambiando la cobertura anual. Los datos aquí referidos corresponden a la consulta de 7 de febrero de 2016.
} 
El análisis de los datos de la EMIF Sur para flujos laborales, se puede hacer mediante la información proporcionada por personas que van en dirección sur-norte - Procedentes de Guatemala a Chiapas- o que van en dirección norte-sur - Procedentes de México a Guatemala-. Para este último flujo, esto es de personas que acaban de pasar por la experiencia de trabajo, a modo de ilustración, se destacan sólo algunas características para el año 2014. En dicho año, se captó información de 629,628 cruces de migrantes guatemaltecos que iban de regreso a hacia Guatemala, de los cuales 623,364 (99\%) corresponde a personas que dijeron haber trabajado en Chiapas, tanto en actividades agrícolas como en no agrícolas. De ese gran total, 426 mil (69\%) son cruces de trabajadores y trabajadoras agropecuarios (TA): 417 mil son cruces de hombres y el resto son cruces de mujeres. Casi la totalidad de cruces (421 mil), corresponde a TA que permanecen más de un día en territorio chiapaneco. En cuanto a los ingresos que perciben, 36\% de los cruces hacen referencia a TA que ganaron hasta un salario mínimo (s.m. $)^{18}$ y $62 \%$ entre uno y dos s.m. Respecto al tipo de documento migratorio para trabajar en México, $86 \%$ corresponde a TA con Tarjeta de Trabajador Fronterizo, 6.7\% con Tarjeta de Visitante Regional o con Forma Migratoria de Visitante Local ${ }^{19}$ y $7 \%$ sin documento.

La EMIF Sur, entonces, nos permite conocer ciertas características, pero es importante insistir que el número de cruces no puede ser usado como indicativo del volumen - personas - de TA. Desde el inicio de su aplicación en 2004, la encuesta ha tenido varios ajustes metodológicos y se han registrado cambios en su cobertura. Por otra parte, no hay que olvidar que se trata de una encuesta basada en información que se capta en ciertos puntos. Por ello, desde nuestro punto de vista, la EMIF Sur es el instrumento idóneo para conocer: las características de la migración, las características y condiciones de quienes participan en

\footnotetext{
${ }^{18}$ El salario vigente en 2014 para la Zona B, que incluía al estado de Chiapas, fue 63.77 pesos diarios. A partir del 1 de enero de 2017, según la resolución de la Comisión Nacional de los Salarios Mínimos (Conasami), publicada en el Diario Oficial de la Federación (DOF), este monto es 80.04 pesos para la llamada Zona Única, en la que ahora se clasifica a todas las entidades federativas (Conasami, 2016).

${ }^{19}$ Aunque con la entrada en vigor de la Ley de Migración el 9 de noviembre de 2012, este documento cambió a una Tarjeta de Visitante Regional, a 2014 aún estaban vigentes FMVL, dado que su vigencia es de cinco años.
} 
ésta, y los cambios en la inserción laboral de migrantes provenientes de Guatemala. Aun así, para determinados aspectos, no se pueden hacer generalizaciones, debido al reducido número de casos en la muestra no expandida, a que su cobertura está focalizada en determinados puntos fronterizos, entre otros aspectos. Con esta consideración, nuestro interés se focaliza principalmente en tratar de entender lo que pasa con la afluencia de trabajadores y trabajadoras y con su circularidad migratoria.

\section{El ordenamiento de flujos y los datos sobre trabajadores agrícolas}

Los trabajadores y las trabajadoras agrícolas (TA) constituyen un flujo migratorio histórico entre Guatemala y México. La gran mayoría ha llegado a Chiapas - y en especial al Soconusco- como parte de un proceso generacional. Este relevo aún se mantiene, pero ya se evidencian cambios importantes. Generaciones más jóvenes han empezado a reorientar su rumbo desde Guatemala a otros destinos. Hay varias causas para este cambio, que merecen un análisis específico, que rebasa los objetivos de este documento, pero del que es posible brindar algunos elementos para tratar de entender los cambios en las tendencias sobre el número de TA y el registro de las entradas a México, haciendo referencia a la movilidad con documentos migratorios.

Ya se señalaba en la introducción a este artículo, que aunque no se cuenta con estadísticas históricas que permitan dar cuenta de la presencia de los y las TA desde que comenzaron a llegar a México desde fines del siglo XIX, sí es posible aludir a la importancia de esta mano de obra en los ciclos agrícolas mediante las estadísticas administrativas del Instituto Nacional de Migración, los resultados de la EMIF Sur y datos derivados de estudios particulares que sobre el tema se han hecho. Con los dos últimos tipos de fuente se pueden conocer algunas de las características de los trabajadores y las trabajadoras agrícolas y parte de las condiciones de vida y de trabajo en Chiapas, pero no los volúmenes.

Hasta mediados de la década del 2000, la literatura sobre la migración de trabajadores agrícolas guatemaltecos a México destacaba la falta de datos o de información para conocer características específicas de esta corriente migratoria (Casillas y Castillo, 1987, Castillo y Casillas, 1988; 
Mosquera, 1990, Castillo, 1992, Ángeles, 2000; Cáceres, 2001; Rojas, 2001; Rojas y Ángeles, 2002). En 1990, Antonio Mosquera hacía un recuento de los intentos de varios autores por estimar el volumen y las características de estos migrantes, pero él mismo señalaba la poca confiabilidad de tales ejercicios (Mosquera, 1990). Ésta era una característica de los registros oficiales tanto de Guatemala como de México en los que no se especificaba el desplazamiento de trabajadores agrícolas a México. Según Antonio Mosquera, a fines de la década de 1980, "ninguno de los dos países recono[cía] estadística alguna sobre los jornaleros agrícolas [...] Además habría que notar que los datos no [eran] confiables" (ibídem: 60).

En la década de 1990, las oficinas de la Dirección General de Servicios Migratorios de la Secretaria de Gobernación de México comenzaron a registrar el ingreso de TA como un flujo particular y no como un agregado de las estadísticas de visitantes locales. En las estadísticas de mediados de dicha década, ya el INM reportaba los montos de permisos que se expedían para autorizar el ingreso de TA, aunque no es muy claro cómo se llevó a cabo el proceso. Carlos Cáceres, por ejemplo, señalaba que en 1993 no había estadísticas de trabajadores agrícolas (Cáceres, 2001); sin embargo, él elaboró una "Relación de trabajadores" del año 1992, a partir de la información contenida en los listados que usaba el INM para la documentación de jornaleros, lo que hace pensar en problemas relacionados con la organización y sistematización de las estadísticas migratorias, más que en la falta de las mismas.

A fines de la década de 1990, algunos de estos problemas subsistían, aunque ya desde 1995, la Delegación Regional de Chiapas del INM generaba la serie estadística anual de trabajadores agrícolas. Con estos registros oficiales, se pueden conocer los volúmenes de entradas documentadas y algunas características de quienes intervienen en dicho flujo. Estas entradas se registraban mediante un permiso temporal que las autoridades migratorias expedían a los y las TA provenientes de Guatemala.

Hasta 1997 e incluso 1998, el permiso migratorio se otorgaba mediante un oficio del Área de No Inmigrantes que se usaba en los puertos fronterizos para documentación colectiva, denominado "Relación de Trabajadores Agrícolas". A partir de octubre de 1997 se 
emitió la autorización para el cambio en el trámite y para la expedición de la Forma Migratoria para Visitantes Agrícolas (FMVA), pero su implementación comenzó en 1998, lo que supuso una serie de ajustes en el proceso de documentación, pues se tenía que llenar un formato individual, por cada titular y por cada acompañante. Con el registro individualizado, en el primer lustro de la década del 2000, el INM promovió la expedición de una credencial con vigencia anual, buscando simplificar los trámites y depurar los registros. Desde 2008, la FMVA se sustituyó por la Forma Migratoria de Trabajador Fronterizo (FMTF), para incorporar a trabajadores no agrícolas, ampliando la cobertura a los cuatros estados de la frontera sur e incluyendo a Belice como país de origen. A partir del 9 de noviembre de 2012, con la publicación del Reglamento de la Ley de Migración, la FMTF se convierte en Tarjeta de Trabajador Fronterizo (TTF).

Durante la década de 1990 (hasta 1997), el INM expidió en promedio por año alrededor de 64 mil permisos a los trabajadores y las trabajadoras de Guatemala para laborar en el estado de Chiapas. En el periodo en que se expidió la FMVA (1998 a 2008), este promedio descendió a alrededor de 46 mil permisos por año. Entre 2008 y 2011, pareciera haber un incremento muy notorio, para luego mantenerse, entre 2012 y 2015, en un promedio de 53 mil entradas (ver Cuadro 1).

Al mismo tiempo que se generaban y sistematizaban de mejor forma estos datos sobre entradas, también se comenzaba la depuración de bases de datos para poder estimar el volumen de trabajadores. La modernización en la infraestructura de INM en los puertos fronterizos y en las oficinas centrales, lo que incluía también la introducción de tecnologías de información y la modernización en el proceso de trámites y expedición de documentos — por ejemplo, la expedición de credenciales con vigencia según el estatus migratorio-, como parte del "ordenamiento" de flujos, pero también como resultado de las observaciones de la Evaluación al Desempeño que la Auditoria Superior de la Federación le hacía al INM. Según este órgano de control federal, el INM tenía serios problemas de confiabilidad en las estadísticas oficiales, no sistematizaba la información — no se desagregaban los 
datos, por ejemplo_-, sus sistemas de registro y control de información eran obsoletos, entre otras deficiencias. ${ }^{20}$

Como resultado de esta sistematización, para el segundo lustro de la década del 2000, ya se contaba con datos sobre el número de trabajadores y trabajadoras con FMTF oTFT, pero en el sitio electrónico de la Unidad de Política Migratoria de la Secretaría de Gobernación, ${ }^{21}$ sólo se puede consultar el periodo 2010-2015. Entonces, si se asume que el registro anual de trabajadores documentados por parte del INM es correcto para este último periodo (ver Gráfica 1) y si se observan los datos de entradas (ver Cuadro 1) para intentar establecer algún tipo correspondencia, lo que se obtiene más bien son interrogantes o dudas: 1) ¿por qué en 2010 y 2011 el número de entradas se disparó notablemente? 2) ¿en esos dos años hubo una mayor circularidad de trabajadores y trabajadoras?22 Y 3) ¿hay un problema de captación de registro, tanto para entradas como para trabajadores/as?

Si hubiese certeza en la sistematización, entonces, se podría estimar el promedio de entradas a México de los y las TA de Guatemala. De cualquier forma, los registros administrativos del INM ya permiten confrontar el número de entradas con el número de TA para los últimos seis años (2010-2015), con lo cual es indispensable profundizar en estudios que sometan a prueba estas estadísticas.

Cuadro 1. México. Entradas documentadas por INM de visitante para trabajo fronterizo, 1995 a 2015.

\begin{tabular}{|c|c|c|c|}
\hline Ańo & $\begin{array}{c}\text { Entradas documentadas } \\
\text { a México (A) }\end{array}$ & $\begin{array}{c}\text { Entradas documentadas } \\
\text { a Chiapas (B) }\end{array}$ & $\begin{array}{c}\text { Entradas documentadas } \\
\text { a Chiapas, trabajadores } \\
\text { agrícolas (C) }\end{array}$ \\
\hline 1995 & 67,737 & 67,737 & 67,737 \\
\hline 1996 & 66,728 & 66,728 & 66,728 \\
\hline
\end{tabular}

\footnotetext{
${ }^{20}$ Se hace referencia a las auditorías al desempeño y financiera de los años 1999 y 2000 a INM, llevadas a cabo por la Auditoría Superior de la Federación (ASF, 2001).

${ }^{21}$ Estas cifras pueden ser consultadas en el sitio electrónico de los Boletines Estadísticos que emite la Unidad de Política Migratoria de la Secretaría de Gobernación (UPM, s.f.). A la fecha de redacción de este artículo, aún no se publicaban los datos completos del año 2016.

${ }^{22}$ Entre 1997 y 1998, con los datos del "Banco de Datos de trabajadores agrícolas", elaborado por Castillo y Ángeles, se identificó que había algunos trabajadores que, durante el año, podían regresar a las unidades productivas hasta nueve veces (Ángeles y Castillo, 1998; Castillo y Ángeles, 2000).
} 


\begin{tabular}{|l|c|c|c|}
\hline 1997 & 67,633 & 67,633 & 67,633 \\
\hline 1998 & 49,655 & 49,655 & 49,655 \\
\hline 1999 & 64,691 & 64,691 & 64,691 \\
\hline 2000 & 69,036 & 69,036 & 69,036 \\
\hline 2001 & 40,640 & 40,640 & 40,640 \\
\hline 2002 & 38,693 & 38,693 & 38,693 \\
\hline 2003 & 45,561 & 45,561 & 45,561 \\
\hline 2004 & 42,895 & 42,895 & 42,895 \\
\hline 2005 & 45,518 & 45,518 & 45,518 \\
\hline 2006 & 40,244 & 40,244 & 40,244 \\
\hline 2007 & 27,840 & 27,840 & 27,840 \\
\hline 2008 & 23,535 & 23,535 & 23,535 \\
\hline 2009 & 46,477 & 46,454 & $45,989^{*}$ \\
\hline 2010 & 84,107 & 84,047 & $83,206^{*}$ \\
\hline 2011 & 130,674 & 130,633 & $129,327^{*}$ \\
\hline 2012 & 61,295 & 61,272 & $60,659^{*}$ \\
\hline 2013 & 55,845 & 55,713 & $54,042^{*}$ \\
\hline 2014 & 45,471 & 45,099 & $43,746^{*}$ \\
\hline 2015 & 53,492 & 53,483 & $52,413^{*}$ \\
\hline
\end{tabular}

* Estimación indirecta para aproximarse al número de entradas de TA a Chiapas que considera el volumen total de éstas con permiso de trabajador fronterizo y la proporción de "extranjeros documentados para trabajar con FMTF/TTF” para actividades agrícolas (ibídem).

Fuente: elaboración propia con base en: 1) de 1995 a 1998, datos proporcionados por la Delegación Regional en Chiapas, INM. 2) de 1999 a 2007, datos tomados de INM (2011). 3) De 2008 a 2015, cuadros estadísticos de UPM (s.f.)

Gráfica 1. Chiapas. Trabajadores y trabajadoras agrícolas con permiso migratorio expedido por INM, 2010-2015.

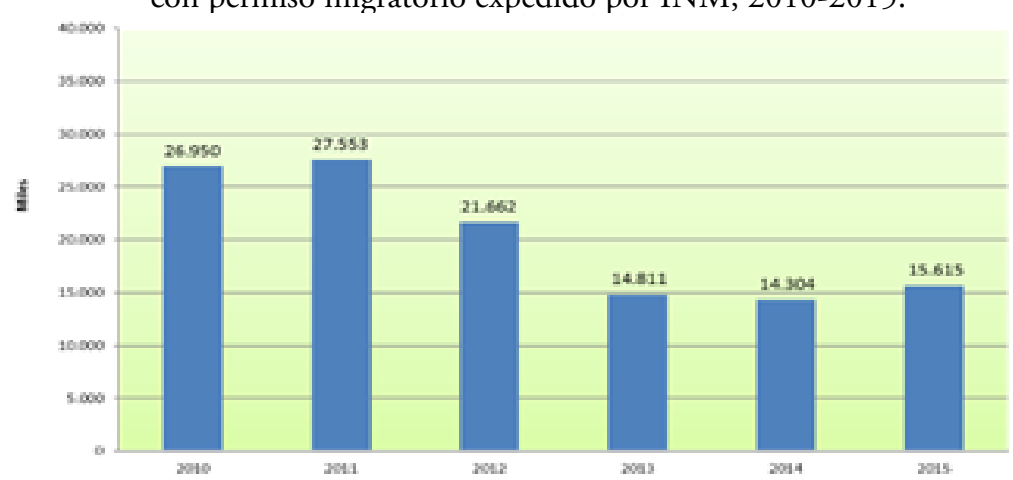


Fuente: Elaboración propia basada en las cifras de "extranjeros documentados para trabajar con FMTF/TTF”, considerando el desglose por sector de actividad, publicadas en UPM (s.f.)

Para cualquier análisis de las tendencias de la movilidad laboral en la frontera Guatemala-México, entonces, hay que ser cautos y más rigurosos con los datos de los registros del INM cuando se hace referencia al número de personas. Además, no hay que perder de vista que junto a los migrantes con permiso que entran al país también hay: 1) un número no determinado de TA que ingresa sin este tipo de permiso, y 2) TA que se documentan con un permiso que no les autoriza trabajar - como la Tarjeta de Visitante Regional.

Estas cifras contrastan notoriamente con las reportadas por Emif Sur, que ya se ilustró con el número de cruces para un año (2014), ya sea considerando el total del flujo de personas o sólo el de trabajadores agrícolas (TA). Sin embargo, es necesario ser enfáticos en que se trata de fuentes de datos con objetivos, metodologías y poblaciones distintas.

\section{Las posibles causas del descenso en el número de trabajadores agrícolas}

Si se consideran las estadísticas del INM relativas al número de trabajadores (Grafica 1), entonces, se estaría registrando un descenso en este número $\mathrm{y}$, por lo tanto, habría una menor afluencia de TA. Esta tendencia descendente no es sólo el resultado de ajustes en el tipo de registro, también da cuenta de otros factores, algunos interrelacionados entre sí, que han impactado el mercado local y la afluencia de TA, como: 1) las crisis en los precios internacionales del café y sus efectos en la economía cafetalera por más de una década, 2) la afectación de cafetales por plagas y enfermedades —en especial, broca y roya-, así como por factores asociados al cambio climático o a fenómenos hidrometeorológicos, 3) la diversificación de actividades - y de ocupaciones - por parte de los TA y 4) la reorientación de los flujos migratorios de Guatemala a otros destinos — por ejemplo, Belice y Estados Unidos_- en alguna medida debido al efecto de políticas de control y de contención migratoria, así como de las acciones de 
restricción al trabajo de personas menores de edad que el propio INM con otras dependencias lleva a cabo.

Las crisis en los precios del café y los desastres ocasionados por fenómenos naturales —en Chiapas, por ejemplo, las depresiones tropicales y el Huracán Stan — han obligado a los empleadores a la diversificación de cultivos y de actividades, lo que ha tenido un impacto en la demanda de mano de obra ocupada en el cultivo y en la cosecha del café. Desde fines de la década de 1990 y principios de la del 2000, cuando se conjuntaron factores climáticos y la crisis en los precios de café, varias de las grandes fincas del Soconusco introdujeron cambios en sus sistemas productivos para diversificar cultivos y no depender sólo de este grano. Entre la diversificación de actividades, se encuentra el ecoturismo, lo que ha permitido a algunas fincas amortiguar la afectación de la roya, por ejemplo. ${ }^{23}$ Otras fincas y ejidos, sin embargo, han sido seriamente afectados por el dańo que ha causado la roya a los cafetales. Varias fincas en el Soconusco, que contrataban mano de obra de Guatemala, han sido abandonadas como consecuencia de este tipo de afectaciones. ${ }^{24} \mathrm{Al}$ respecto, se argumenta que no es redituable la producción de café y, por tanto, pagar mano de obra para recuperar cultivos y sembrar variedades resistentes a enfermedades y plagas, en especial, si no hay apoyos gubernamentales para recuperarse de este tipo de afectaciones.

Ejidatarios que, en algún momento contrataron mano de obra guatemalteca, ya no lo hacen porque no pueden pagarla. Don Francisco, ejidatario de Unión Juárez, a quien entrevistamos para indagar por la baja en la afluencia de TA, señalaba que por esta localidad llegaron a pasar "hasta 70 mil trabajadores", pero que ahora ya no pasan. Posiblemente, hay un sobredimensionamiento de su parte respecto al número, pero sí hay un notorio cambio en la afluencia. Unión Juárez fue un punto importante para la entrada de TA que se documentaban

${ }^{23}$ Varias fincas ubicadas en la llamada Ruta del café, en la región del Soconusco, han impulsado el ecoturismo: Irlanda, Argovia, Hamburgo, La Chiripa y Santa Rita. Una alternativa que sólo es solución para algunos productores

${ }^{24}$ El delegado de la Asociación Agrícola de Productores de Café en la región Soconusco, en una entrevista en 2015 de la prensa local en Chiapas, comentaba que pensaron que varias de las fincas abandonadas podían habilitarse para el turismo, pero que los diagnósticos no les mostraron viabilidad para adaptar los espacios con ese fin, por lo que desistieron (El Sie7e de Chiapas, 2015). 
en la oficina del Instituto Nacional de Migración. Al respecto, Don Francisco, señala:

Ahora sí, mire, se nos vino para abajo nuestras cosechas. Estamos pasando una crisis durísima [...] se acabaron los apoyos económicos [...] Todos los campesinos estamos arruinados, mire. Sí, todos los campesinos. Malísimo con los precios del café ¡No sé qué pasa! ¿Por qué el gobierno no mete las manos para exportar ese café? [...] [MR: ¿contrata usted a trabajadores guatemaltecos?] No, ya no. Dejaron de venir. Ya no, ya no vienen por aquí. Se fueron pa'l norte. Venían muchos señores, ya grandes de edad; también venían muchachos, señoras. Pero ya no; se fueron pa'l norte. Se fueron a ganar más, ya no se quedaron aquí con nosotros [...] Ya no vienen; ni uno [...] Aquí entraban. Pasaban por migración; allí se legalizaban y de allí se los llevaba el contratista para las fincas, por el Edén, por Nueva Alemania [...] Todas esas fincas grandes. Pero, según me han platicado, ahora, en todas esas fincas grandes, ya se acabó el café (Don Francisco, ejidatario, Unión Juárez, 23 de enero de 2017).

También los habitantes de Unión Juárez, que es una localidad colindante con Guatemala y muy próxima a varios de los municipios guatemaltecos que tradicionalmente han sido proveedores de mano de obra, como Tacaná, Sibinal y Tajumulco, en el Departamento de San Marcos, hacen referencia al descenso en la afluencia de trabajadores.

Sí, ha habido un descenso. Antes los jornaleros guatemaltecos se veían en el parque [de Unión Juárez]; dormían en las cocinas de los ejidatarios hasta quince de ellos. Ahora, ya no. El que puede contratar lo hace con cinco jornaleros y no necesariamente de Guatemala; pero son muy pocos los que lo hacen (Ernesto, vecino de Unión Juárez, 15 de enero de 2017)

En el testimonio de Don Francisco, se aporta un elemento que ha sido característico de los últimos años y que ha repercutido de distinta manera en la llegada de trabajadores de Guatemala a México: la acentuación 
en la precarización laboral, en particular en las modalidades y monto del pago. A esto hay que sumarle, el efecto de la devaluación del peso mexicano. Hace 30 ańos los trabajadores percibían que ganaban un poco más que en Guatemala, hace 15-20 años percibían que no ganaban más, pero que "tenían trabajo seguro" (es decir, que seguro conseguían trabajo); hoy muchos dicen que "no coordina", tal como lo confirman Carol Girón ${ }^{25}$ y un representante del Movimiento de Trabajadores Campesinos de Guatemala (MTC) ${ }^{26}$ :

hay comunidades en las cuales ha disminuido la migración al sur de México a partir de la devaluación del peso, eso sinceramente es innegable. Para ellos "ya no trae cuenta" (Carol Girón, 11 de mayo de 2016).

Hacia las fincas de café, banano y otros, ha disminuido [la migración]. Pero, en la juventud, en señoritas, jóvenes, niños ha aumentado hacia las ciudades de México y Estados Unidos de América [MR: ¿por qué?] Por el tipo de cambio de moneda [...] (Representante del MTC, San Marcos, Guatemala, 17 de mayo de 2016)

Los y las TA pueden conseguir trabajo en México, aunque en términos reales lo que se les paga sólo alcanza para subsistir. Pero, hay TA que consideran que no vale el esfuerzo de llegar a Chiapas a trabajar. Muchos siguen viniendo porque no hay alternativa en Guatemala; lo que ganan no les alcanza, pero en Guatemala no tienen posibilidades de cultivar la tierra, si es que tienen alguna microparcela. A principios de la década del 2000, una mujer originaria de Concepción Tutuapa, entrevistada como parte del proyecto sobre la participación de mujeres en la migración

\footnotetext{
${ }^{25}$ Directora del Programa Misioneros de San Carlos Scalabrinianos, de Guatemala, quien ha analizado las características y condiciones laborales de los trabajadores agrícolas, con énfasis en la nińez trabajadora, Entrevista de monitoreo a las condiciones laborales de las trabajadoras agrícolas, derivado del Proyecto "La participación de mujeres y menores en la migración laboral agrícola guatemalteca”, coordinado por Martha Luz Rojas Wiesner.

${ }^{26}$ Líder del Movimiento de Trabajadores Campesinos, San Marcos, Guatemala, organización que se ha focalizado en la defensa de los derechos de los trabajadores, incluyendo migrantes a México y a otros países. Entrevista de monitoreo a las condiciones laborales de las trabajadoras agrícolas, derivado del Proyecto "La participación de mujeres y menores en la migración laboral agrícola guatemalteca”, coordinado por Martha Luz Rojas Wiesner.
} 
laboral guatemalteca (Rojas y Ángeles, 2001), decía claramente que lo que ganaban en Chiapas sólo les servía "nomás para caminar nuestro tiempo". ${ }^{27}$ Una frase que aún sigue vigente, como lo expresó Sandra Herrera Ruiz en el año 2003, un poco después de comenzar una de las crisis en los precios del café, pero que aplica para las circunstancias actuales:

La migración estacional al interior del país [Guatemala] y hacia la frontera con México ha sido un factor estructural del trabajo agrícola. Sin embargo, la migración internacional al convertirse en estrategia de sobrevivencia para familias completas, implica una nueva forma de refugio contra la pobreza extrema de Guatemala. Podríamos identificar un nuevo tipo de migración internacional forzada producto de la inestabilidad económica y social producto de la crisis del café y de la exclusión social de Guatemala (2003: 4).

En entrevista a jornaleros guatemaltecos en Unión Juárez, en enero de 2017, relativa a los montos de los jornales en distintas actividades del cultivo y cosecha del café, se hacía referencia a las siguientes cifras: en México se pagan 100 pesos por la jornada para el desombre — podar o quitar la sombra de los árboles-; entre 70 y 80 pesos por una jornada para poda, deshije u otras actividades del cultivo; entre 40 y 50 pesos la limpia de una cuerda -25 metros cuadrados-. En tiempos de pisca, 100 pesos por una caja de $68 \mathrm{~kg}$. En Guatemala, por su parte, 50 quetzales el desombre; 40 quetzales la poda y el deshije; 50 quetzales por una caja de $68 \mathrm{~kg}$. En México, aproximadamente, 40 quetzales son 100 pesos. En Guatemala, 100 pesos equivalen a 38 quetzales. ${ }^{28}$ Aparentemente, lo que se gana en uno y otro lado es similar, pero al retornar a Guatemala hay gastos que realizan los y las TA y lo que ganan en México no les alcanza para satisfacer sus necesidades básicas.

A esto hay que agregar que, en varias fincas, se ha abusado en los pagos. En mayo de 2016, por ejemplo, el Movimiento de Trabajadores Campesinos (MTC) de Guatemala llamaba la atención sobre un tipo de pago denominado "productividad asignada": con el mismo

${ }^{27}$ Entrevista en Concepción Tutuapa, 2001

${ }^{28}$ Tipo de cambio 1 peso mexicano=0,36 quetzales ( 29 de enero de 2017). 
monto con el que se pagaba por limpiar dos cuerdas (60 pesos), en el primer semestre de 2016, se exigía limpiar tres, aunque no se concluyese el trabajo el mismo día. Si el trabajador no cumplía con la productividad, se le hacía el descuento correspondiente. Además, había casos en que se incumplía con los pagos, o no se les pagaba, en especial si los y las TA llegaban de manera voluntaria, ${ }^{29}$ con o sin Tarjeta de Trabajador Fronterizo. En mayo de 2016, se preparaba una comisión en la que participaría el representante del MTC, personal de consulado de Guatemala en Tapachula y personal del INM para una visita de inspección en junio a tres fincas en Tapachula que habían sido denunciadas por este tipo de abusos. ${ }^{30}$

En particular en esta reorientación del flujo migratorio hacia otros destinos, jugó un papel importante la negativa de las autoridades migratorias mexicanas al ingreso de personas menores de 14 años, que se produjo entre los ańos 2001 y $2003,{ }^{31}$ un poco después de la ratificación (30 de marzo de 2000) y la entrada en vigor (19 de noviembre de 2000) del Convenio sobre las peores formas de trabajo infantil (núm. 182), pero también en un contexto en el que el INM comenzaba a preocuparse por el "ordenamiento" de los flujos migratorios en la frontera sur de México y por la depuración de estadísticas migratorias. Igualmente, la restricción se vinculaba a la exigencia a autoridades mexicanas y a los consulados guatemaltecos para controlar la trata de personas en sus distintas modalidades. ${ }^{32}$

Esta restricción se ha seguido aplicando, limitando la edad permitida para la documentación como trabajador fronterizo a los 16 años. Así, personas menores de 16 años no pueden ser documentadas como trabajadoras. Además, quienes tengan entre 16 y 18 ańos,

29 "Trabajador voluntario" es una denominación usada en las fincas para hacer referencia a TA que llegan directamente a las fincas a contratarse sin un intermediario. La expresión comenzó a ser usada también por el INM para referirse a trabajadores y trabajadoras que, de manera autónoma o independiente, se documentan con una TTF para ir por su cuenta a una unidad productiva.

${ }^{30}$ Entrevista telefónica a representante del MTC, San Marcos, 17 de mayo de 2016.

${ }^{31}$ Notas de campo del Proyecto "La participación de mujeres y menores en la migración laboral agrícola guatemalteca en la región del Soconusco, Chiapas”, coordinado por Martha Luz Rojas (2001), y financiado por Sistema de Investigación Benito Juárez, del Conacyt.

32 Entrevista a Alfredo Valladares, Cónsul de Guatemala en Ciudad Hidalgo, ciudad Hidalgo, 20 de marzo de 2007. 
deben presentar original y copia de su documento de identidad y de "un documento certificado por un juez de paz donde el padre o tutor lo autorice para trabajar en territorio nacional". ${ }^{33}$ La vigilancia en el cumplimiento de esta medida no sólo se ha aplicado en los puntos fronterizos de internación, sino en las fincas mediante visitas de verificación migratoria, las cuales se comenzaron a realizar más frecuentemente cuando se aprobó la Ley de Migración en 2011. En estos operativos del INM, se han identificado fincas que emplean a menores de 16 años, quienes vienen en algún grupo familiar o de personas que decidieron no hacer el trámite migratorio para evitar ser regresados a los lugares de origen. Las restricciones a la documentación de menores de edad han generado la búsqueda de alternativas para un ingreso no documentado de personas en este rango de edades, en particular de 14 a 18 años. $^{34}$ Según el representante del MTC, ${ }^{35}$ un mismo grupo familiar puede tener integrantes que estén trabajando en la misma finca con la TTF — mayores de 16 o de 18 años_, mientras que otra parte no cuentan con dicho documento - menores de 16 años- La necesidad de ganar un poco más de recursos para el grupo familiar, ha forzado la búsqueda de alternativas que invisibilizan a las personas menores de edad y las condiciones de mayor precariedad en las que trabajan.

Las visitas de verificación migratoria del INM no se centran en la vigilancia de las condiciones laborales, sino en las migratorias y en el cumplimiento de la disposición relativa a la edad de los y las TA. Ester, ${ }^{36}$ por ejemplo, alude a estas visitas y a la preocupación del INM para que no haya menores de edad trabajando.

\footnotetext{
${ }^{33}$ Circular de difusión en la que se señalan los requisitos para el trámite, que se distribuye en las instalaciones de las subdelegaciones del INM donde se hacen trámites para la TTF, como, por ejemplo, en la llamada Casa Roja —oficina del INM en Talismán.

${ }^{34}$ Son múltiples las barreras que enfrentan los menores de 18 años para lograr la autorización para trabajar en México, lo que incluye el trato despótico de algunos oficiales de migración cuando, por ejemplo, después de haber caminado 12 horas desde su casa para llegar al sitio de documentación, se les dice que deben regresarse porque les falta algún documento. A esto se suman los obstáculos que deben superar para poder trabajar en alguna finca porque en su casa esperan que lleve algún recurso. Incertidumbre, desesperanza, frustración y enfado son algunos de los sentimientos que los motivan a buscar alternativas.

${ }^{35}$ Entrevista telefónica, 17 de mayo de 2016

${ }^{36}$ Seudónimo
} 
Así como ahorita yo no estoy trabajando en la finca porque están pidiendo pase de trabajo [...] Ahorita, entra la migración ${ }^{37}$ en la finca, y menores no tienen derecho de trabajar y solo mayores. Piden su pase de trabajo, piden papeles. Si tienen pase de trabajo, tienen derecho de trabajar, si no, no (Ester, 29 años, trabajadora agrícola, Tapachula, 30 de octubre de 2016).

Esta vigilancia ha forzado a Ester a vivir con sus hijos y a trabajar en un ejido, mientras su esposo trabaja en una finca, pues él sí cuenta con "pase de trabajo" — se refiere a la TTF_ y ella no. Ester no puede hacer el trámite de documentación porque dice que "piden 600 pesos por el pase”. Esa fue la información que le dio su tío, quien hizo el trámite la semana anterior. ${ }^{38}$

En estas visitas a las fincas y en los operativos móviles, el INM ha detenido a TA. Algunos han sido llevados a la Estación Migratoria Siglo XXI para su deportación. Ese hecho también ha causado malestar por parte de los y las TA, para quienes estar detenidos en la estación migratoria es equivalente a estar en la cárcel, lo que en las comunidades de origen no sólo es mal visto, también causa vergüenza a la familia. ${ }^{39}$ Aunque históricamente ha habido controles a la movilidad de TA, las restricciones derivadas del control migratorio implementadas desde fines de la década de 1990 han incidido en la adopción de algunas estrategias de los y las TA para evitarlos; sin embargo, con las visitas de verificación a las unidades productivas para pedir documentos han tenido que recurrir a otras, como la invisibilización. Ester, por ejemplo, no sale del ejido donde trabaja, por lo que su permanencia se ha prolongado, pero vive con muchas limitaciones. Según ella,

\footnotetext{
${ }^{37}$ Se refiere al Instituto Nacional de Migración.

${ }^{38}$ El dato quizás es incorrecto, pero sí hay un cobro. Según la página de trámites del INM, consultada el 30 de enero de 2017, el costo es de 339 pesos para este documento (INM, 2017). De acuerdo con la Ley Federal de Derechos, el pago puede ser exento si se demuestra que se ganará "un salario mínimo". Si el s. m. vigente es de 80.04 pesos, una persona que gana entre 70 y 80 pesos, no debería pagar por la TTF; pero si el jornal es de 100 pesos, por ejemplo, lo que se paga por un jornal de desombre, entonces, sí tendría que pagar. Si ese jornal es el ingreso único de un grupo familiar, entonces, es imposible pagar por el documento.

${ }^{39}$ Conversación con líderes comunitarios en Concepción Tutuapa, San Marcos (febrero de 2016).
} 
...antes no pedían nada, mamita, pero ahorita sí, piden. Piden, de pedir, piden pase de trabajo o pase de visitante de acá, ahorita; pero antes, no. Podía uno cruzar y venir a todas partes; hasta me llevó mi patrona a conocer de Tabasco, me llevó a conocer hasta allá de Puebla, porque tenía carro (Ester, 29 ańos, trabajadora agrícola, Tapachula, 30 de octubre de 2016)

En este contexto restrictivo, ha habido una reorientación de flujos. Una parte se ha quedado en Guatemala para ocuparse en otras actividades, otra se ha dirigido a Belice y a los Estados Unidos, tanto para laborar en actividades agrícolas como no agrícolas, y solo una parte sigue llegando a México, a distintas localidades no necesariamente fronterizas, pero a distintas ocupaciones en servicios y en el comercio. En el Perfil Migratorio de Guatemala (OIM, 2012), ya se mencionaba la diversificación de destinos en el caso de la emigración guatemalteca. Carol Girón confirma esta reorientación:

Hay otras comunidades que están experimentando nuevos patrones migratorios, y más redireccionados a las áreas urbanas, especialmente de la capital de Guatemala, como posibles opciones y etapas de prueba. Se observa en la mayoría de mujeres y hombres jóvenes entre 20 y 30 años (Carol Girón, 11 de mayo de 2016).

Por otra parte, están los efectos de una política de contención que produce "ilegalidad" o "irregularidad" que, a su vez, produce exclusión, así como distintas expresiones de discriminación social que criminalizan a las personas migrantes, incluyendo a trabajadores y trabajadoras.

\section{Reflexiones finales}

A pesar de que la presencia y la contribución de los trabajadores y las trabajadoras agrícolas de Guatemala siguen siendo fundamentales para la economía agrícola del estado de Chiapas, hay evidencias de una disminución en el número de quienes siguen llegando de manera estacional a las fincas y ejidos del estado de Chiapas. Hay varios factores que han incidido en esta dinámica, entre los cuales las medidas de control 
migratorio tienen un peso significativo, agudizando la precariedad y acentuando la vulnerabilidad a la violencia, a la deportación y a la explotación de migrantes laborales en el territorio chiapaneco.

Desde mediados de la década de 1990, hay evidencia de una mejora en la captación y sistematización de información por parte de las autoridades migratorias de México, relativa a las personas que cruzan la frontera terrestre en la franja limítrofe de Guatemala con México con fines laborales. En particular en la década del 2000, el enfoque de gestión de la migración del gobierno mexicano aceleró estos procesos. Básicamente, con lo que se contaba era con datos de entradas y no de personas. Muchos de los análisis se basan en el uso de estas estadísticas para referirse a las tendencias de la migración laboral en la frontera sur de México. Pero, hay que ser cautos en el tipo de afirmaciones que se hacen al respecto.

Con el mejoramiento en la calidad de las fuentes, ahora hay muchos más interrogantes que antes para tratar de entender los efectos que varios factores -interrelaciones entre sí, o no- están teniendo en los distintos tipos de movilidad, sea temporal o estacional, cotidiana $-\mathrm{O}$ commuting - y de asentamiento o mayor permanencia. No se puede seguir pensando en los procesos de manera aislada.

En las dos últimas décadas se ha evidenciado que, junto a problemas asociados a factores económicos y ambientales, acciones gubernamentales en México como las dirigidas a la "erradicación del trabajo infantil”, sin ofrecer alternativas para mejorar los ingresos de las familias, y las medidas de control y contención de migrantes, han tenido distintas repercusiones: en la reorientación de los flujos migratorios de Guatemala a otros países; en el mayor grado de incertidumbre, frustración y desesperanza en jóvenes que buscan trabajar para "completar el gasto" para sí o para sus familias; han propiciado categorías de extranjeros, irregularidad y deportabilidad; y han derivado en estrategias de invisibilización entre los propios migrantes que fomentan nuevas formas de explotación y de mayor precariedad, entre otras consecuencias.

Todo ello sin dejar claro cuál es, entonces, el objetivo del "ordenamiento" de la migración y de la documentación migratoria. En 
el discurso y en los textos de la legislación migratoria o en los programas se enuncia la protección de las personas, el respeto a sus derechos, la vigilancia de su cumplimiento. Sin embargo, hay acciones que tienen efectos negativos. Se diseñan programas sin tener un conocimiento preciso de las características de la dinámica migratoria transfronteriza, de las condiciones de vida y de trabajo en estos contextos. Se conoce parte de lo que sucede en algunas de las fincas y ejidos en México, pero poco sobre los lugares de origen. Las autoridades laborales deben hacer las supervisiones necesarias en los lugares de trabajo para garantizar que los empleadores cumplan con proporcionar a los trabajadores las condiciones de un trabajo decente, tal como lo marcan la Organización Internacional del Trabajo y los acuerdos internacionales que se han suscrito, en particular la Convención de los derechos de todos los trabajadores y sus familias (1990), pero también hay que analizar cuáles son las repercusiones de algunas de estas disposiciones a nivel internacional que se aplican sin conocer los contextos y sin ofrecer o crear alternativas. Entre otros temas de enorme relevancia, hay que preguntarse por las alternativas a la erradicación del trabajo infantil, reconociendo el punto de vista de las personas migrantes.

En 2014, se firmó un Acuerdo laboral entre el Ministerio de Trabajo de Guatemala y la Secretaría de Trabajo y Previsión Social de México, con el que se pretende formular un programa binacional. Sin embargo, es imperativo llamar la atención que, en más de 20 años, se han tomado acuerdos de este tipo, se han realizado múltiples reuniones de carácter binacional, se han llevado a cabo distintos foros, pero las condiciones laborales de los y las TA de Guatemala en México no han mejorado.

Si bien en el último lustro se han impulsado programas que otorgan apoyos — por ejemplo, Sedesol_ para mejorar las instalaciones y la infraestructura para albergar a los trabajadores en las fincas, lamentablemente no es una situación generalizable. Sólo en algunas fincas han mejorado las condiciones en las que viven los y las TA, pero la gran mayoría de las instalaciones ofrece deficiencias y condiciones precarias. Además, el tema de las instalaciones es sólo una de varias preocupaciones relacionadas con el trato digno a TA y a las familias que llegan con ellos o ellas. 
Finalmente, se requiere que las estadísticas que se producen sobre los trabajadores abunden más en la publicación de variables por flujo migratorio y por ocupación, desglosada por sexo, para que la información que cuesta tanto dinero generar sea usada en mayor medida y, además, por personas interesadas en la protección a los trabajadores y las trabajadoras, sin que necesariamente sean expertos en estadística. No se trata de "ordenar" los datos para el control migratorio, sino de que sean instrumento para la toma de decisiones con enfoque de derechos humanos y para los monitoreos sociales.

\section{Bibliografía citada}

Ángeles Cruz, Hugo Manuel, 1998, "Migraciones laborales en la frontera México-Guatemala”, Ponencia presentada en el Congreso Anual de Investigación de El Colegio de la Frontera Sur, San Cristóbal de Las Casas, Chiapas.

Ángeles Cruz, Hugo, 2000, "Características sociodemográficas de los trabajadores agrícolas guatemaltecos en el Soconusco, Chiapas", Migración Internacional, año 4, núm. 12 (Boletín editado por Conapo), México, D.F., pp. 13-16.

Ángeles Cruz, Hugo, 2009, "Características de los trabajadores agrícolas guatemaltecos en México según la EMIF GUAMEX”, en María Eugenia Anguiano y Rodolfo Corona Vázquez (coordinadores), Flujos migratorios en la frontera Guatemala-México, Centro de Estudios Migratorios del INM, Secretaría de Gobernación, El Colegio de la Frontera Norte, México, D.F., pp. 157-198.

Ángeles Cruz, Hugo y Manuel Ángel Castillo, 1998, Banco de Datos sobre trabajadores agrícolas guatemaltecos en la región del Soconusco, Chiapas, El Colegio de la Frontera Sur, El Colegio de México, Instituto Nacional de Migración, Tapachula, Chiapas (inédito). Bartra, Armando, 1995, "Origen y claves del sistema finquero del Soconusco", en Chiapas 1, ERA, Instituto de Investigaciones Económicas UNAM, México, D.F., pp.29-52.

Basok, Tanya, Danièle Bélanger, Martha Luz Rojas Wiesner y Guillermo Candiz, 2015, Rethinking Transit Migration. Precarity, Mobility, 
and Self-Making in Mexico, Palgrave Macmillan, Basingstoke, Hampshire, UK.

Bustamante, Jorge, 1989, "Frontera México-Estados Unidos: reflexiones para un marco teórico", Frontera Norte, vol. I, núm. 1, enerojunio, pp. 7-24.

Cáceres Ruiz, Carlos, 2001, Migrantes guatemaltecos en México, Comodes, Guatemala.

Casillas, Rodolfo y Manuel Ángel Castillo, 1987, Impactos regionales de las migraciones internacionales a la frontera sur de México. El Caso de los trabajadores estacionales, Informe técnico final, Centro de Estudios Demográficos y de Desarrollo Urbano, El Colegio de México, Consejo Nacional de Ciencia y Tecnología, México, D.F. (mimeo).

Castillo, Manuel Ángel, 1992, "Migraciones laborales en la frontera sur: ¿Un fenómeno en proceso de cambio?”, en Humberto Muñoz, (compilador), Población y sociedad en México, Coordinación de Humanidades UNAM, Miguel Ángel Porrúa, México, D. F., pp. 173-192.

Castillo, Manuel Ángel y Hugo Ángeles Cruz, 2000, “La participación laboral de los trabajadores agrícolas guatemaltecos en el Soconusco, Chiapas", ponencia presentada en la VI Reunión de Investigación Demográfica en México "Balance y Perspectivas de la Demografía Nacional ante el Nuevo Milenio", Somede, México, D.F., 31 de julio a 4 de agosto.

Castillo, Manuel Ángel y Mónica Toussaint, 2010, "Seguridad y migración en la frontera sur”, en Arturo Alvarado y Mónica Serrano (editores), Seguridad nacional y seguridad interior, El Colegio de México, México, D.F.

Castillo, Manuel Ángel y Rodolfo Casillas, 1988, "Características básicas de la migración guatemalteca al Soconusco Chiapaneco”, Estudios Demográficos y Urbanos, vol. 3, núm. 3, septiembrediciembre, pp. 537-562.

De Genova, Nicholas, 2002, “Migrant 'illegality' and deportability in everyday life", Annual Review of Anthropology, vol. 31, núm. 1, pp. 419-447. 
De Genova, Nicholas, 2004, "The legal production of mexican/migrant 'illegality”, Latino Studies, núm. 2, pp. 160-185.

García de León, Antonio, 1985, Resistencia y utopía. Memorial de agravios y crónica de revueltas y profecías acaecidas en la provincia de Chiapas durante los últimos quinientos años de su historia, Tomo I, ERA, México, D.F.

García Ortega, Martha, 2013, “Migraciones laborales, derechos humanos y cooperación internacional. Cortadores de caña centroamericanos en la frontera México-Belice", Trace, núm. 63, junio, pp. 7-23.

Goldring, Luin y Patricia Landolt, 2011, "Caught in the WorkCitizenship Matrix: The Lasting Effects of Precarious Legal Status on Work for Toronto Immigrants", Globalizations, vol. 8, núm. 3, pp. 325-341.

González Cámara, Noelia, 2010, "De indeseables a ilegales: una aproximación a la irregularidad migratoria", ARBOR Ciencia, Pensamiento y Cultura, vol. CLXXXVI, núm. 744, pp. 671-687. Grollová, Daniela, 1995, "Los trabajadores cafetaleros y el partido socialista chiapaneco. 1920-1927", en Juan Pedro Viqueira y Mario Humberto Ruz (editores), Chiapas. Los rumbos de otra historia, Instituto de Investigaciones Filológicas UNAM, CIESAS, pp. 195-214.

Herrera Ruiz, Sandra, 2003, “Trabajadores agrícolas temporales en la frontera Guatemala-México”, Ponencia presentada en Tercera Conferencia Internacional Población del Istmo Centroamericano, Costa Rica, 17-19 de noviembre.

Instituto Nacional de Migración (INM), 2005, Propuesta de politica migratoria integral de la frontera sur de México, INM, México, D.F. Instituto Nacional de Migración (INM), 2011, “Trabajadores guatemaltecos documentados con la Forma Migratoria de Visitante Agrícola (FMVA) en el estado de Chiapas", Dossier, 31 de octubre.

Isacson, Adam, Maureen Meyer y Gabriela Morales, 2014, Mexico's Other Border: Security, Migration, and the Humanitarian Crisis at the line with Central America, WOLA, Washington D.C. 
Knippen, José, Clay Boggs y Maureen Meyer, 2015, Un camino incierto. Justicia para delitos y violaciones a los derechos humanos contra personas migrantes y refugiadas en México, Informe de investigación, WOLA, noviembre.

López Sala, Ana María, 2006, “Derechos de ciudadanía y estratificación cívica en sociedades de inmigración”, en Ignacio Campoy (editor), Una discusión sobre la universalidad de los derechos humanos y la inmigración, Dykinson, Universidad Carlos III, Madrid, pp. 129-151.

López-Sala, Ana y Dirk Godenau, 2015, “En torno a la circularidad migratoria: aproximaciones conceptuales, dimensiones teóricas y prácticas políticas”, Migraciones, núm. 38, diciembre, pp. 9-34. Martínez Velasco, Germán, 1994, Plantaciones, trabajo guatemalteco y politica migratoria en la frontera sur de México, Gobierno del Estado de Chiapas, Instituto Chiapaneco de Cultura, Ocozocuautla, Chiapas.

Mosquera Aguilar, Antonio, 1990, Trabajadores guatemaltecos en México. Consideraciones sobre la corriente migratoria de trabajadores guatemaltecos estacionales a Chiapas, México, Tiempos Modernos, Guatemala.

Ordóñez Morales, César E., 1993, Eslabones de frontera. Un análisis sobre aspectos de desarrollo agrícola y migración de fuerza de trabajo en regiones fronterizas de Chiapas y Guatemala, Universidad Autónoma de Chiapas, Tuxtla Gutiérrez, Chiapas.

Organización Internacional para las Migraciones (OIM), 2012, Perfil Migratorio de Guatemala, OIM, Guatemala.

Pastoral de Movilidad Humana de la Conferencia Episcopal de Guatemala (PMH-CEG), 2013, La roya del café. Sus efectos directos en la pérdida de empleo y emigración, Boletín núm. 2, julio, Guatemala.

Rojas Wiesner, Martha Luz, 2001, "Mujeres trabajadoras agrícolas guatemaltecas en la frontera sur de México", Entre Redes, Boletín Trimestral, núm. 5, Sin Fronteras I.A.P., pp. 19-21.

Rojas Wiesner, Martha Luz, 2010, “Migración y educación en regiones fronterizas. El caso de los migrantes centroamericanos en 
Chiapas, un tema pendiente", Educación Superior y Sociedad, año 15, núm. 2, julio-diciembre, pp. 133-161.

Rojas Wiesner, Martha Luz, 2012, "Migración de trabajadoras agrícolas guatemaltecas a México. Modalidades de contratación y de trabajo", ponencia presentada en el $V$ Congreso de la Asociación Latinoamericana de Población Las transiciones en América Latina y el Caribe. Cambios demográficos y desafios sociales presentes $y$ futuros, ALAP, Montevideo, Uruguay, 23 a 26 de octubre.

Rojas Wiesner, Martha y Hugo Ángeles Cruz, 2001, "Más que acompañantes... trabajadoras agrícolas. Mujeres migrantes en la frontera México-Guatemala", Travesaño 2000. Temas de población, Revista del Consejo Estatal de Población del Estado de Guanajuato, año 4, núm. 9, noviembre, pp. 3-8.

Rojas Wiesner, Martha y Hugo Ángeles Cruz, 2002, Participación de mujeres y menores en la migración laboral agrícola guatemalteca a la región del Soconusco, Informe Técnico al Sistema de Investigación Benito Juárez (SIBEJ), El Colegio de la Frontera Sur, Tapachula, Chiapas (inédito).

Rojas Wiesner, Martha Luz y María De Vargas, 2014, "Strategic Invisibility as Everyday Politics for a Life with Dignity: Guatemalan Women Migrants' Experiences of Insecurity at Mexico's Southern Border", en Thanh-Dam Truong, Des Gasper, Jeff Handmaker y Sylvia I. Bergh (editores), Migration, Gender and Social Justice, Springer, Berlin, pp. 193-211.

Sin Fronteras, 2008, Cambiando perspectivas: de la gestión de flujos hacia la construcción de políticas de migración con enfoque de desarrollo, Sin Fronteras I.A.P., México, D.F.

Spenser, Daniela, 1984, "Trabajo forzado en Guatemala, bracerismo guatemalteco en Chiapas", Cuicuilco. Revista de la Escuela Nacional de Antropología e Historia, núm. 12, enero, pp. 5-10.

Wasserstrom, Roberto, 1976, "El bracerismo guatemalteco en Chiapas, ¿un motivo de orgullo para el pueblo mexicano?”, Punto Crítico, año $\mathrm{V}$, núm. 62, 9 de septiembre, pp. 11-12.

Weiss, Thomas Lothar y Rodolfo Franco Franco, 2013, "La gestión migratoria en México, avances y retos", en Raúl Plasencia 
Villanueva (coordinador), México, movilidad y migración, Comisión Nacional de Derechos Humanos, México, D.F., pp. 177-193.

\section{Referencias electrónicas}

Auditoría Superior de la Federación (ASF), 2001, Informe de una auditoría al desempeño y una financiera al Instituto Nacional de Migración, [en línea] disponible en http:/www.asf.gob.mx/ Trans/Informes/IR2000i/ir2000/Tomos/Tomo2/INM.htm [fecha de consulta: 3 de mayo de 2017].

Comisión Nacional de Salarios Mínimos (Conasami), 2016, "Resolución de H. Consejo de Representantes de la Comisión Nacional de los Salarios Mínimos que fija los salarios mínimos general y profesionales vigentes a partir de $1^{\circ}$ de enero de $2017^{\prime \prime}$ (DOF, 19 de diciembre de 2016), en Secretaría de Hacienda y Crédito Público, Salarios mínimos 2017, [en línea] disponible en http://www.sat.gob.mx/informacion_fiscal/tablas_indicadores/ Paginas/salarios_minimos.aspx [fecha de consulta: 16 de enero de 2017].

El Sie7e, 2015, "Solo 11 fincas cafetaleras producen en el Soconusco", El Sie7e. El medio de todas las voces de Chiapas, 27 de octubre de 2015, [en línea] disponible en http://www.sie7edechiapas.com/ single-post/2015/10/27/Solo-11-fincas-cafetaleras-producenen-el-Soconusco [fecha de consulta: 19 de enero de 2017].

Encuesta sobre Migración en la Frontera Sur de México, s.f., El Colegio de la Frontera Norte (Colef), Secretaría del Trabajo y Previsión Social (STyPS), Consejo Nacional de Población (Conapo), Unidad de Política Migratoria (UPM), Secretaría de Relaciones Exteriores (SRE), Consejo Nacional para Prevenir la Discriminación (Conapred), [en línea] disponible en http://www.colef.mx/emif [consultado en distintas fechas de 2016 y 2017].

Instituto Nacional de Estadística y Geografía (Inegi), 2011, "Población ocupada y su distribución porcentual según vector de actividad económica para cada municipio", en Censo de Población y Vivienda 2010, [en línea] disponible en http://www.beta.inegi. 
org.mx/proyectos/ccpv/2010/ [fecha de consulta: 17 de enero de 2017].

Instituto Nacional de Migración (INM), 2011, “Trabajadores guatemaltecos documentados con la Forma Migratoria de Visitante Agrícola (FMVA) en el estado de Chiapas", INM, México, actualizado a 31 de octubre de 2011.

Instituto Nacional de Migración (INM), 2017, "Costos", en Tarjeta de Visitante Trabajador Fronterizo, [en linea] disponible en https:// www.gob.mx/tramites/ficha/tarjeta-de-visitante-trabajadorfronterizo/INM275 [fecha de consulta: 30 de enero de 2017]. Secretaría de Gobierno de Chiapas, 2011, Decreto 2010, Periódico Oficial, No. 299, [en líniea] disponible en http://www.sgg. chiapas.gob.mx/po06/2011? $\mathrm{m}=5 \& \mathrm{p}=$ [fecha de consulta: 9 de enero de 2017].

Unidad de Política Migratoria (UPM), s.f., "Boletín Estadístico Anual" [2010 a 2015], en Boletines Estadisticos, [en línea] disponible en http://www.politicamigratoria.gob.mx/es_mx/SEGOB/Estadistica [consultado en distintas fechas en 2016 y hasta 20 de enero de 2017]. 